\title{
Rate and clinical predictors of malignancy in thyroid nodules with indeterminate cytology
}

\author{
Feron Getachew ${ }^{\mathrm{a},}{ }^{,}$, Endale Anberber ${ }^{\mathrm{a}}$ \\ ${ }^{a}$ Department of surgery, Tikur Anbessa Specialized Hospital, College of Health Sciences, Addis Ababa University, Addis Ababa, Ethio- \\ pia.
}

\begin{abstract}
Background: Fine needle aspiration cytology (FNAC) cannot differentiate between benign and malignant conditions in cytologically indeterminate thyroid lesions. Therefore, a minimum of diagnostic lobectomy is required for definitive diagnosis. The objective of this study is to identify the rate of malignancy and clinical features that may possibly predict malignancy in patients with these lesions, in Ethiopian hospitals.

Methods: This was a retrospective review of the medical records of patients who underwent surgery for cytologically indeterminate thyroid lesions in three referral hospitals between September 2015 and September 2020 .

Results: Of 85 patients with indeterminate cytology findings, 54 (63.5\%) were follicular, and 29 (34.1\%) were reported to be hurthle cell neoplasms. Follicular lesions of undetermined significance (FLUS) and suspicious for follicular neoplasm were each reported in single cases (1.7\%). Malignant disease was diagnosed in 19 $(22.4 \%)$ of patients. A follicular variant of papillary cancer was detected in 7 (8.23\%) patients. Hard nodule consistency was reported in 9 of 19 malignant lesions and 5 of 66 benign lesions. In multivariate binary logistic regression, hard nodule consistency was found to be associated with malignancy $(P=0.012$, AOR $=7.28(1.5$, 34.54) $95 \%$ CI ). The ill-defined surface of a nodule was found to be associated with malignancy though the association was not statistically significant $(P=0.088, \mathrm{AOR}=0.162(0.020,1.313) 95 \%$ CI. Ultrasound evaluation of thyroid nodule was performed only in $39(45.8 \%)$ of patients.

Conclusion: The rate of malignancy in thyroid nodules with indeterminate cytology was $22.4 \%$. The risk of malignancy was higher in patients with hard thyroid nodule consistency and ill-defined surface. Despite the established benefits of ultrasound for the evaluation of thyroid nodules, the current practice of its use in our setup is suboptimal.

Keywords: Follicular; hurthle cell; indeterminate cytology; predictors of malignancy
\end{abstract}

\section{INTRODUCTION}

FNAC of the thyroid can generally differentiate between benign and malignant lesions except when the findings are suggestive of atypia of undetermined

*Corresponding author: Feron Getachew

Mailing address: Department of surgery, Tikur Anbessa Specialized Hospital, College of Health Sciences, Addis Ababa University, Addis Ababa, Ethiopia.

E-mail: getferon@gmail.com

Received: 08 October 2021 / Accepted: 20 December 2021 significance (AUS), follicular lesion of undetermined significance (FLUS), suspicious of follicular neoplasm, follicular neoplasm, or hurthle cell neoplasms ${ }^{[1,2]}$. Follicular thyroid lesions are common cytological findings during the evaluation of thyroid nodules. Differentiating follicular thyroid cancer \& Hurthle cell cancer from thyroid adenoma cannot be made by FNAC alone; rather, it requires histological evidence of vascular and capsular invasion ${ }^{[2]}$.

In $70-80 \%$ of cases, nodules with cytological diagnosis of follicular neoplasms turn out to be benign ${ }^{[2]}$. Many patients with benign thyroid disease are thus 
subjected to potentially avoidable surgery (diagnostic lobectomy) and the associated cost. Likewise, the diagnostic confusion exposes patients with malignant disease that may potentially benefit from a single initial total or near-total thyroidectomy to undergo two surgeries. i.e., initial diagnostic Lobectomy and repeat surgery (completion thyroidectomy). Therefore, identifying factors that predict malignancy preoperatively may avoid unnecessary surgery, along with its cost and complications. Accordingly, there has been growing interest among researchers to predict malignancy preoperatively using different parameters such as clinical, ultrasound, cytological, and molecular techniques ${ }^{[3-}$

${ }^{6}$. The intraoperative frozen section has been used in an attempt to define the adequate extent of surgery intraoperatively, but its routine use is quite limited ${ }^{[7]}$. Despite these attempts, most of the results are inconsistent and sometimes contradictory. In developing nations, such as our country, the decision-making process is primarily clinical in part due to the unavailability of advanced diagnostic modalities. Therefore, we seek to identify if there are clinical predictors of malignancy that can guide the choice and extent of therapy.

\section{MATERIALS AND METHODS}

This was a retrospective cross-sectional review of charts in patients who underwent thyroid surgery between September 2015 and September 2020 for cytologically indeterminate thyroid nodules. All patients operated with the FNAC diagnosis of FLUS, AUS, hurthle cell neoplasm, suspicious for follicular neoplasm or follicular neoplasm were selected from the operation room logbooks of Tikur Anbessa, Yekatit 12, and Zewditu memorial hospitals which are located in Addis Ababa, Ethiopia. Cases with recurrence or with inconclusive or lost biopsy results were excluded from the study.

FNAC and biopsy were reported by different pathologists from AAU, TASH, or other institutions. Almost all FNA procedures were performed without ultrasound guidance. The Bethesda system was used to classify the FNA results. Definitive diagnosis of malignancy was determined based on the postoperative histopathological diagnosis. Demographic, clinical, and laboratory data as well as pathology reports were reviewed from individual patient charts. Sociodemographic data, mass characteristics including size, surface, consistency, and type of nodule as well as signs \& symptoms such as rapid tumor growth, change of voice, dysphagia, airway obstruction, and duration of illness were analyzed for association with the presence of malignancy. SPSS version 24 was used for data analysis.

Categorical data were presented as percentages and frequencies of occurrence. Continuous variables were described as means and standard deviations Associations between categorical variables were checked with chi-square test. Univariately associated variables were subjected to multivariate analysis

The degree of association was calculated using binary logistic regression, with a statistically significant cutoff $(P<0.05)$.

Ethical approval was obtained from the research and ethics committee at the Department of Surgery, Addis Ababa University.

\section{RESULTS}

\section{Demographic data}

The number of patients operated on in the three hospitals with the diagnosis of follicular or hurthle cell thyroid neoplasm in 5 years was 115. Patients that fulfill the inclusion criteria were 85. FNA was taken without ultrasound guidance, in almost all of the patients. The follicular neoplasm was diagnosed in $54(63.5 \%)$ and hurthle cell neoplasm in 29 (34.1\%)

The mean age of presentation was $35.64+12.823$ (age range 18-78) years. Among all patients, $70.6 \%$ were younger than 40 while $5.9 \%$ were older than 60 . $74(87.1 \%)$ were female and $11(12.9 \%)$ were male. The male to female ratio is $1: 6.72$. The vast majority of patients $(77,90.6 \%)$ were from Addis Ababa. The comparison between benign and malignant lesions is provided in Table 1 below.

\section{Clinical presentation}

The mean duration of symptoms for all the patients was $4.68+6.28$ (range, 15 days to 30 years). All patients had complaints of anterior neck swelling. None of the patients had a history of exposure to radiation or a family history of thyroid cancer. Other presenting complaints were as follows: pressure sensation 20 (23.5\%), history of rapid growth 11 (12.9\%), hoarseness of voice in $8(9.4 \%)$ difficulty of swallowing 5 (5.9\%), a symptom of airway obstruction 1 (1.2\%). The comparison between the presentation of benign and malignant lesions is provided below in Table 2 .

\section{Physical examination findings}

The mean size of the tumor was $4.77+2.21 \mathrm{~cm}$, ranging from $1 \mathrm{~cm}$ to $15 \mathrm{~cm}$. Based on size category, most patients $(60,70.6 \%)$ have size $>3.0 \mathrm{~cm}$. Multinodular 
Table 1. Comparison of demographic data among patients with benign and malignant nodules.

\begin{tabular}{llll}
\hline Variables & Benign nodules $(\boldsymbol{n}=\mathbf{6 6})$ & Malignant $(\boldsymbol{n}=\mathbf{1 9})$ & $\boldsymbol{P}$-value \\
\hline $\begin{array}{l}\text { Age at diagnosis (year) + SD } \\
\text { Age category (\%) }\end{array}$ & $36+13.2$ & $34+11.3$ & 0.176 \\
$<40$ & $72.70 \%$ & $63.20 \%$ & \\
$40-60$ & $19.70 \%$ & $36.80 \%$ & \\
$>60$ & $7.60 \%$ & $0.00 \%$ & 0.722 \\
Sex: no (\%) & & & \\
Male & $9(13.84 \%)$ & $2(11.76 \%)$ & \\
Female & $56(86.15 \%)$ & $17(89.47 \%)$ & \\
M: F & $1: 7.3$ & $1: 9.5$ & 0.110 \\
FNAC (\%) & & $4(21.10 \%)$ & \\
Hurthle cell neoplasm & $25(37.90 \%)$ & $15(79 \%)$ & 0.706 \\
Follicular neoplasm & $39(59 \%)$ & & \\
Thyrotoxicosis, no (\%) & & & \\
\hline
\end{tabular}

Table 2. Presenting symptoms among patients with benign and malignant thyroid nodules.

\begin{tabular}{llll}
\hline Symptoms: $\boldsymbol{n}$ (\%) & Benign nodules (66) & Malignant (19) & $\begin{array}{l}\text { Univariate } \begin{array}{l}\text { Multivariate } \\
\boldsymbol{P} \text {-value }\end{array} \\
\text {-value }\end{array}$ \\
\hline Pressure sensation 16 (18.8\%) & $11(68.75 \%)$ & $5(31.25 \%)$ & 0.347 \\
Neck swelling $85(100 \%)$ & $66(77.60 \%)$ & $19(22.40 \%)$ & \\
Rapid Growth $11(12.9 \%)$ & $6(54.54 \%)$ & $5(45.45 \%)$ & 0.059 \\
Change of voice 8 (9.4\%) & $7(87.50 \%)$ & $1(12.80 \%)$ & 0.491 \\
Difficulty of swallowing 5 (5.9\%) & $4(80.00 \%)$ & $1(20.00 \%)$ & 0.897 \\
Signs and symptoms of airway obstruction 1(1.2\%) & 0 & 1 & 1.000 \\
Family history of thyroid cancer (0\%) & 0 & 0 & \\
Radiation exposure to head and Neck (0\%) & 0 & 0 & \\
Mean duration of symptoms (years) & $4.8 \pm 6.5(0.04-30)$ & $4.2 \pm 5.38(0.08-20)$ & 0.679 \\
\hline
\end{tabular}

goiter is the commonest type of swelling $(59,69.4 \%)$ followed by solitary nodule $(23,27.1 \%)$, and diffuse $(3$, $3.5 \%)$ swelling. Firm consistency was the commonest $(63,74.1 \%)$ followed by hard $(14,16.5 \%)$, and soft $(8$, 9.4\%) consistency. Most swellings (70, 82.4\%) have smooth nodule surface whereas 10 (11.8\%) of the nodules had irregular/ill-defined surfaces. The surface was not described in 5 (5.9\%) patients 'charts. Lymphadenopathy is seen in $3(3.5 \%)$ patients. Based on preoperative serum TSH level measurement, 73 (85.9\%) of the patients were found to be euthyroid. Hypothyroidism is documented in $1(1.2 \%)$ whereas thyrotoxicosis in 11 (12.9\%). Physical findings in relation to the risk of malignancy are illustrated in Table 3.

Imaging

Ultrasound of the thyroid, as an investigation modality for nodule evaluation, was used only in 39 (45.8\%) patients. The rest of the patients underwent surgery based on clinical assessment, evaluation of thyroid function, and FNAC alone.

\section{Definitive diagnosis}

Definitive diagnosis of malignancy was made in 19 (22.4\%) cases by postoperative histopathology evaluation. The remaining 66 (77.6\%) were benign cases. Among the malignant lesions, papillary carcinoma is the leading malignancy $(11,12.9 \%)$ followed by follicular carcinoma $(5,5.88 \%)$; anaplastic cancer $(2,2.35$ $\%)$; hurthle cell cancer $(1,1.17 \%)$. One of the five follicular carcinomas was a minimally invasive encapsulated variant.

Hurthle cell neoplasm accounts for 8 cases (9.4\%); hurthle cell adenoma 7 (8.2\%) and hurthle cell carcinoma $1(1.2 \%$,). Benign conditions consisted of follicular adenoma $(30,35.2 \%)$, colloid goiter $(24,28.2 \%)$, 
Table 3. Physical findings and predictors of malignancy determined by univariate \&multivariate analysis.

\begin{tabular}{|c|c|c|c|c|}
\hline $\begin{array}{l}\text { Nodule Characteristics } \\
(n=85)\end{array}$ & Benign nodules (66) & Malignant (19) & $\begin{array}{l}\text { Univariate } \\
P \text {-value }\end{array}$ & $\begin{array}{l}\text { Multivariate } \\
P \text {-value }\end{array}$ \\
\hline Nodule consistency no (\%) & & & $<0.01$ & 0.012 \\
\hline Hard $14(16.5 \%)$ & $5(35.70 \%)$ & $9(64.30 \%)$ & & \\
\hline Firm $63(74.1 \%)$ & $54(85.70 \%)$ & $9(14.30 \%)$ & & \\
\hline Soft $8(9.4 \%)$ & $7(87.50 \%)$ & $1(12.50 \%)$ & & \\
\hline Surface of the nodule, no (\%) & & & $<0.01$ & 0.088 \\
\hline Ill-defined 10 (11.8\%) & $3(30.00 \%)$ & $7(70.00 \%)$ & & \\
\hline Smooth $70(82.4 \%)$ & $60(85.70 \%)$ & $10(14.30 \%)$ & & \\
\hline Missing $5(5.9 \%)$ & 3 & 2 & & \\
\hline Nodule size, cm & & & 0.558 & \\
\hline Mean + SD & $4.62+2.24$ & $5.28+2.10$ & & \\
\hline$>3 \mathrm{~cm}$ & 46 & 14 & & \\
\hline$<3 \mathrm{~cm}$ & 19 & 4 & & \\
\hline Missing & 1 & 1 & & \\
\hline Type of nodule (\%) & & & 0.626 & \\
\hline MNG $59(69.4 \%)$ & $12(20.33 \%)$ & 47 (79.66\%) & & \\
\hline Solitary 23 (27.1\%) & $7(30.43 \%)$ & $16(69.56 \%)$ & & \\
\hline Diffuse $3(3.5 \%)$ & 3 & 0 & & \\
\hline \multicolumn{5}{|l|}{ Other characteristics $n(\%)$} \\
\hline Tenderness 4 (4.7\%) & 2 & 2 & 0.220 & \\
\hline Fixity $2(2.4 \%)$ & 1 & 1 & 0.398 & \\
\hline Lymphadenopathy 3 (3.5\%) & 2 & 1 & 0.677 & \\
\hline Intraoperative evidence of malignancy 5 (5.9\%) & 2 & 3 & 0.061 & 0.898 \\
\hline
\end{tabular}

Table 4. Comparison between preoperative FNA diagnosis and biopsy results.

\begin{tabular}{|c|c|c|c|c|}
\hline & Pathology & FN & HCN & Total \\
\hline Malignant & Papillary cancer & 10 & 1 & $11(12.9 \%)$ \\
\hline \multirow[t]{3}{*}{$19(22.4 \%)$} & Follicular cancer & 4 & 1 & $5(5.8 \%)$ \\
\hline & Anaplastic cancer & 1 & 1 & $2(2.4 \%)$ \\
\hline & Hurthle cell carcinoma & 0 & 1 & $1(1.2 \%)$ \\
\hline Benign & Follicular adenoma & 18 & 8 & $26(32.9 \%)$ \\
\hline \multirow[t]{5}{*}{$66(77.6 \%)$} & Colloid goiter & 15 & 5 & $20(23.5 \%)$ \\
\hline & Hurthle cell adenoma & 0 & 7 & $7(8.2 \%)$ \\
\hline & Adenomatoid hyperplasia & 4 & 2 & $6(7.1 \%)$ \\
\hline & Riedel thyroiditis & 1 & 0 & $1(1.2 \%)$ \\
\hline & Hashimoto thyroiditis & 1 & 3 & $4(4.7 \%)$ \\
\hline
\end{tabular}


Hashimoto thyroiditis $(4,4.7 \%)$, and Riedel thyroiditis $(1,1.2 \%)$. Comparison between cytologically indeterminate diagnosis and postoperative definitive diagnosis with biopsy is depicted in Table 4 .

\section{Predictors of malignancy}

On univariate analysis, rapid growth $(P=0.049)$, hard consistency of a nodule, and irregular surface of a nodule showed association (each with $P<0.01$ ). Other variables didn't show any association with malignancy both in univariate, and bivariate analysis.

On multivariate analysis we have found that hard consistency is associated with thyroid malignancy with a $P$-value of $0.012, \mathrm{AOR}=7.28(1.5,34.54) 95 \% \mathrm{CI}$ and irregular surface of the nodule found to have marginal association; $P=0.088, \mathrm{AOR}=0.162(0.020,1.313) 95 \%$ CI (Table 3)

\section{DISCUSSION}

FNA cytology is generally a reliable diagnostic test in differentiating between benign and malignant thyroid lesions except in cytologically indeterminate lesions. The Bethesda System is the most widely used and standardized tool for the communication of thyroid cytopathology ${ }^{[1]}$. FLUS, AUS, follicular neoplasms, and hurthle cell neoplasms are considered to be cytologically indeterminate. In this group of lesions, an accurate distinction between benign and malignant disease cannot be made as cytology analyzes only individual cell characteristics without basement membrane, and the difference depends on the presence and absence of architectural features of capsular and vascular invasion.

A diagnosis of follicular neoplasm accounted for $63.5 \%$ of the indeterminate cytology whereas hurthle cell neoplasm was $34.1 \%$. Single cases of FLUS and Suspicious of Follicular Neoplasm were also found. Our study found an overdiagnosis of hurthle cell neoplasm (34.1\%) on preoperative cytology compared to less than $12 \%$ in other studies ${ }^{[8,9]}$. HCNs are considered variants of follicular neoplasms by many authors ${ }^{[10]}$. However, WHO classification considers Hurthle cell tumors as a separate entity due to their peculiar genetic profile, biological profile, and clinical features ${ }^{[1]}$. The risk of malignancy is thought to be higher in these lesions compared to follicular neoplasms ${ }^{[12]}$. But this is challenged by others ${ }^{[13,14]}$.

Hurthle cells can be found in different reactive, inflammatory, and neoplastic processes of the thyroid. For a lesion to be diagnosed as HCN, it should be encapsu- lated and predominantly consist of hurthle cells. The amount of hurthle cells required for the diagnosis of HCN has been defined variably in the literature. Most authors state $75 \%{ }^{[8,15,16]}$ or $50 \%{ }^{[17,18]}$ as a defining value. In our setup, pathologists use variable cutoff values. In the present study, only 8 out of 29 cytologically diagnosed hurthle cell neoplasms were truly HCN on definitive pathology diagnosis and only 1 of 29 cytologically diagnosed HCN neoplasms turned out to be HCC. Therefore, in our institutions, cytologic diagnosis of HCN is not reliable and it is not associated with increased risk of malignancy. Although, the number of definitively diagnosed HCNs is too small in order to make any meaningful statistical correlation.

Common biopsy findings after thyroidectomy for cytologically indeterminate thyroid lesions include Follicular adenoma, adenomatoid hyperplasia, follicular carcinoma, follicular variant of papillary cancer, and classical papillary cancer ${ }^{[8,9,15]}$. The incidence of malignancy in cytologically indeterminate nodules ranges from $14 \%$ to $48.5 \%{ }^{[8,9,13,15]}$. The incidence of malignancy in the present study was $22.4 \%$; which is comparable with most of the reports.

Follicular variants of papillary cancer, classical papillary cancer, and follicular thyroid cancers are malignancies that are commonly found in such lesions ${ }^{[8,9,19]}$. Rarely, others such as medullary and anaplastic cancers have been reported ${ }^{[9,20]}$. Likewise, in the present study, the follicular variant of papillary cancer was the leading type, which accounted for 7 out of 19 malignant nodules followed by follicular thyroid cancer ${ }^{[5,19]}$. The total number of papillary cancer cases including the classical variant was 11 .

Different clinical features have been described as predictors of malignancy in thyroid nodules. These include the history of hoarseness of voice, history of the rapid growth of the nodule, fixation to surrounding structures, hard consistency of the nodule, and the illdefined surface of the nodule ${ }^{[21,22]}$. Furthermore, old age, male sex, solitary nodule, and larger size of the nodule are thought to be associated with increased risk of malignancy ${ }^{[9,23]}$. In contrast, others reported that old age, male sex, larger nodule size, and solitary nodule are not predictive of malignancy ${ }^{[4,24]}$. Large nodule size has been defined variably among different researchers including $>3 \mathrm{~cm}{ }^{[9]},>4 \mathrm{~cm}{ }^{[4]}$. In the present study, we arbitrarily used the former. Only the hard consistency of a nodule on physical examination was found to be associated with malignancy. Of the 15 nodules that were hard on palpation 9 (64.3\%) were 
malignant. High rates of malignancy in hard nodules were reported in other studies where the study group was not limited to indeterminate cytology ${ }^{[25,26]}$.

The ill-defined surface of a nodule, usually assessed by ultrasound, is suggested to be associated with malignancy ${ }^{[27,28]}$. In the present study, the ill-defined surface of a nodule (irregularity) was documented based on physical examination finding only. However, there was a marginal correlation with malignancy, though it was not statistically significant. Even though there was no association with the larger size, it can be noted that the mean size was slightly larger in malignant nodules.

Sonographic features (such as microcalcification, hypoechoic pattern, irregular borders), high serum thyroglobulin concentration, genetic markers, as well as molecular markers such as BRAF, galectin-3, RAS, RET/ PTC, and cytokeratin are associated with a high risk of malignancy ${ }^{[4,15,29,30]}$. In our series, only $45.8 \%$ of patients had an ultrasound done for evaluation of thyroid nodule. Most of these didn't document a complete description of a nodule. None of the patients had serum Thyroglobulin determined as it is not readily available in our country. The same thing is true for genetic and molecular means. Therefore, we couldn't analyze these parameters as predictors of malignancy.

Though its reliability is questionable, the frozen section is sometimes used to identify malignancy intraoperatively and hence define the extent of surgery ${ }^{[7}$, ${ }^{24]}$. We attempted to evaluate intraoperative clinical evidence of malignancy as frozen section evaluation is not available in our setup. Intraoperative features of malignancy were present in a total of 5 patients, among which 3 had malignancy. One of the 5 patients had extensive fixity of the nodule to the surrounding structures; hence malignancy was considered intraoperatively though nothing more than debulking could be done. Eventually, a post-operative biopsy revealed Riedel thyroiditis.

Certain risk factors for the development of thyroid cancer include being exposed to ionizing radiation at a young age, having a first-degree relative with thyroid cancer, and chronic TSH stimulation in endemic goitrous areas ${ }^{[31,32]}$. None of our patients had these risk factors.

We attempted to find out if the patients are from an endemic area. Unfortunately, it was not possible to determine that because many patients registered only their tentative address during the treatment period (not the permanent address of their residence). Accordingly, about $90 \%$ of the patients appeared to be from Addis
Ababa, which is iodine sufficient. Therefore, the meaningful association could not be assessed. Likewise, we had only one patient with high serum TSH who was already on treatment.

\section{CONCLUSION}

The rate of malignancy in thyroid nodules with indeterminate cytology was $22.4 \%$. Hard nodule consistency on physical examination was found to be associated with an increased risk of thyroid malignancy. The irregular surface of a nodule is marginally associated with malignancy. However other clinical parameters such as older age, large nodule size, and solitary nodule didn't show any association. FNAC is found to be inaccurate in differentiating between hurthle cell and follicular neoplasms. The routine use of ultrasound for the evaluation of thyroid nodules with cytological diagnosis of follicular or hurthle cell neoplasms in Ethiopian hospitals is low.

\section{Operational definition}

Consistency of swelling: described as firm, soft, or hard from physical examination findings of the most senior examiner.

The size of the nodule: It was described in centimters measured along its largest dimension.

Duration of symptoms: It described in years. When a patient's complaint was less than a year, it is stated infractions.

Type of swelling: described as solitary, multinodular, or diffuse goiter from physical examination by the most senior examiner.

Rapid growth: subjective complaint of the patient claiming that there is a recent fast growth of thyroid swelling.

Intraoperative evidence of malignancy: Intraopertive features include infiltration or fixity to surrounding structures /gross extrathyroidal extension, tumor thrombus in middle thyroid and/or jugular veins, lymph node involvement, and fragile mass.

\begin{tabular}{ll}
\hline Abbreviations & \\
\hline AAU & Addis Ababa University \\
FN & Follicular neoplasm \\
FNAC & Fine needle aspiration cytology \\
HCC & Hurthle Cell Carcinoma \\
HCN & Hurthle Cell Neoplasm \\
OR & Odds Ratio \\
TASH & Tikur Anbessa Specialized Hospital \\
\hline
\end{tabular}




\section{DECLARATIONS}

\section{Availability of data and materials}

A soft copy of all data used for this article are available at the corresponding author, it can be made acquired at a reasonable request.

\section{Financial support and sponsorship}

To conduct this research, the corresponding author received funding from the College of Health Sciences, Addis Ababa University.

\section{Conflicts of interest}

All authors declared that there are no conflicts of interest.

\section{Ethical approval and consent to participate}

The study complied with the Declaration of Helsinki and was approved by the Research \& Ethical committee of the department of surgery College of health science, Addis Ababa University.

\section{REFERENCES}

1. Theoharis, C. G., Schofield, K. M., Hammers, L., Udelsman, R., \& Chhieng, D. C. (2009). The Bethesda thyroid fine-needle aspiration classification system: year 1 at an academic institution. Thyroid, 19(11), 1215-1223.

2. Cibas, E. S., \& Ali, S. Z. (2017). The 2017 Bethesda system for reporting thyroid cytopathology. Thyroid, 27(11), 1341-1346.

3. Davis, N. L., Gordon, M., Germann, E., Robins, R. E., \& McGregor, G. I. (1991). Clinical parameters predictive of malignancy of thyroid follicular neoplasms. The American journal of surgery, 161(5), 567-569.

4. Gulcelik, N. E., Gulcelik, M. A., \& Kuru, B. (2008). Risk of malignancy in patients with follicular neoplasm: predictive value of clinical and ultrasonographic features. Archives of Otolaryngology-Head \& Neck Surgery, 134(12), 1312-1315.

5. Melck, A. L., \& Yip, L. (2012). Predicting malignancy in thyroid nodules: Molecular advances. Head \& neck, 34(9), 1355-1361.

6. Hawasli, A., Rizzo, P., Khoury, H., \& McCaffrey, J. L. (2002). Can fine-needle aspiration biopsy of thyroid nodule help in determining the extent of surgery in follicular and Hurthle cell neoplasm at a community teaching institution? Am Surg, 68(10),
907.

7. Najah, H., \& Tresallet, C. (2019). Role of frozen section in the surgical management of indeterminate thyroid nodules. Gland surgery, 8(Suppl 2), S112.

8. McHenry, C. R., Thomas, S. R., Slusarczyk, S. J., \& Khiyami, A. (1999). Follicular or Hürthle cell neoplasm of the thyroid: Can clinical factors be used to predict carcinoma and determine extent of thyroidectomy? Surgery, 126(4), 798-804.

9. Baloch, Z. W., Fleisher, S., LiVolsi, V. A., \& Gupta, P. K. (2002). Diagnosis of "follicular neoplasm": a gray zone in thyroid fine-needle aspiration cytology. Diagnostic cytopathology, 26(1), 41-44.

10. Ahmadi, S., \& Stang, M. (2016). Hürthle cell carcinoma: current perspectives. OncoTargets and therapy, 9, 6873.

11. Klöppel, G., Couvelard, A., Hruban, R., Klimstra, D., Komminoth, P., Osamura, R., ... \& Rindi, G. (2017). WHO classification of tumours of endocrine organs. Lyon, France: World Health Organization.

12. Zdon, M. J., Fredland, A. J., \& Zaret, P. H. (2001). Follicular neoplasms of the thyroid: predictors of malignancy? Am Surg, 67(9), 880.

13. Öz, B., Doğan, S., Emek, E., Akyüz, M., Akcan, A., Sözüer, E., ... \& Arslan, E. (2018). Predictive Factors of Malignancy in Cytology of Indeterminate Follicular and Hürthle Cell Neoplasms of the Thyroid Gland. International Surgery, 103(1-2), 9-14.

14. Ren, Y., Kyriazidis, N., Faquin, W. C., Soylu, S., Kamani, D., Saade, R., ... \& Stathatos, N. (2020). The presence of Hürthle cells does not increase the risk of malignancy in most Bethesda categories in thyroid fine-needle aspirates. Thyroid, 30(3), 425431.

15. Lee, K. H., Shin, J. H., Ko, E. S., Hahn, S. Y., Kim, J. S., Kim, J.-H., \& Oh, Y. L. (2013). Predictive factors of malignancy in patients with cytologically suspicious for Hurthle cell neoplasm of thyroid nodules. International Journal of Surgery, 11(9), 898-902.

16. Kroeker, T., Prisman, E., Shah, M., MacMillan, C., \& Freeman, J. (2014). Hurthle cell lesions-a retrospective review of final surgical pathology. Thyroid Disord Ther, 3(155), 2.

17. Melck, A., Bugis, S., Baliski, C., Irvine, R., Anderson, D., Wilkins, G., ... \& Wiseman, S. (2006). Hemithyroidectomy: the preferred initial surgical approach for management of Hurthle cell neoplasm. The American journal of surgery, 191(5), 593-597.

18. Hudak, K., Mazeh, H., Sippel, R. S., \& Chen, H. (2012). Hürthle cell metaplasia on fine-needle aspiration 
biopsy is not by itself an indication for thyroid surgery. The American journal of surgery, 203(3), 287-291.

19. Lee, S. H., Baek, J. S., Lee, J. Y., Lim, J. A., Cho, S. Y., Lee, T. H., ... \& Kim, M. J. (2013). Predictive factors of malignancy in thyroid nodules with a cytological diagnosis of follicular neoplasm. Endocrine pathology, 24(4), 177-183.

20. Doddi, S., Chohda, E., Maghsoudi, S., Sheehan, L., Sinha, A., Chandak, P., \& Sinha, P. (2015). The final outcome of indeterminate cytology of thyroid nodules in a District General Hospital. Il Giornale di chirurgia, 36(3), 122.

21. Mittal, M., Ganakumar, V., Shukla, R., \& Kumar, G. M. (2020). Thyroid Nodule: Approach and Management.

22. Schlinkert, R. T., Van Heerden, J. A., Goellner, J. R., Gharib, H., Smith, S. L., Rosales, R. F., \& Weaver, A. L., editors. Factors that predict malignant thyroid lesions when fine-needle aspiration is "suspicious for follicular neoplasm". Mayo Clinic Proceedings; 1997 : Elsevier.

23. Trimboli, P., Condorelli, E., Catania, A., \& Sorrenti, S. (2009). Clinical and ultrasound parameters in the approach to thyroid nodules cytologically classified as indeterminate neoplasm. Diagnostic cytopathology, 37(10), 783-785.

24. You, S. H., Jung, C. K., Chae, B. J., Song, B. J., Jung, S. S., \& Bae, J. S. (2012). Predictive Factors of Malignancy in Thyroid Nodules Diagnosed as Follicular Neoplasm or Hürthle Cell Neoplasm on FNA. Korean Journal of Endocrine Surgery, 12(4), 231-238.

25. Christensen, S., Bondeson, L., Ericsson, U., \& Lindholm, K. (1984). Prediction of malignancy in the solitary thyroid nodule by physical examination, thyroid scan, fine-needle biopsy and serum thy- roglobulin. A prospective study of 100 surgically treated patients. Acta chirurgica scandinavica, 150(6), 433-439.

26. Dedivitis, R. A., do Couto Netto, S. D., de Castro, M. A. F., Pfuetzenreiter Jr, E. G., Nardi, C. E. M., \& de Barbara, E. C. D. (2010). Predictive Value for Malignancy of the Thyroid Nodule Macroscopically. Arquivos Internacionais de Otorrinolaringologia, 14(02), 225-230.

27. Moon, W.-J., Jung, S. L., Lee, J. H., Na, D. G., Baek, J.-H., Lee, Y. H., ... \& Lee, D. H. (2008). Benign and malignant thyroid nodules: US differentiationmulticenter retrospective study. Radiology, 247(3), 762-770.

28. Takashima, S., Fukuda, H., Nomura, N., Kishimoto, H., Kim, T., \& Kobayashi, T. (1995). Thyroid nodules: re-evaluation with ultrasound. Journal of clinical ultrasound, 23(3), 179-184.

29. Bartolazzi, A., Orlandi, F., Saggiorato, E., Volante, M., Arecco, F., Rossetto, R., ... \& Bussolati, G. (2008). Galectin-3-expression analysis in the surgical selection of follicular thyroid nodules with indeterminate fine-needle aspiration cytology: a prospective multicentre study. The lancet oncology, 9(6), 543-549.

30. Nikiforov, Y. E., Steward, D. L., Robinson-Smith, T. M., Haugen, B. R., Klopper, J. P., Zhu, Z., ... \& Nikiforova, M. N. (2009). Molecular testing for mutations in improving the fine-needle aspiration diagnosis of thyroid nodules. The Journal of Clinical Endocrinology \& Metabolism, 94(6), 2092-2098.

31. Feldt-Rasmussen, U. (2001). Iodine and cancer. Thyroid, 11(5), 483-486.

32. Liu, Y., Su, L., \& Xiao, H. (2017). Review of factors related to the thyroid cancer epidemic. International journal of endocrinology, 2017. 